\title{
Formula-feeding practice and associated factors among urban and rural mothers with infants $0-6$ months of age: a comparative study in Jimma zone Western Ethiopia
}

Lakew Abebe ${ }^{1}$, Mamusha Aman ${ }^{1}$, Shifera Asfaw ${ }^{1}$, Hailay Gebreyesus ${ }^{2^{*}}$, Mebrahtu Teweldemedhin $^{3}$ and Abebe Mamo'

\begin{abstract}
Background: Infants are in a state of rapid development and maturation; the growth rate is most rapid during the first 4 to 6 months of life. Few studies indicated that in developing countries including Ethiopia the prevalence and duration of breastfeeding is declining and being replaced by formula milk. Therefore, this study aimed to assess the formula-feeding practice and its associated factors among urban and rural mothers with infants 0-6 months of age in the Jimma Zone, Western Ethiopia.

Methods: A community-based cross-sectional study was conducted from November 7, 2015, to January 10, 2016, in the Jimma Zone. The quantitative data were collected from a sample of 714 respondents using a multistage sampling technique. Data were collected through a structured questionnaire and the multivariate logistic regression model was used to show predictors of the formula-feeding practice among mothers with infants 0-6 months of age.

Result: The proportion of mothers who feed their baby formula-based was $47.2 \%$, of which $34.5 \%$ were living in rural areas and $65.5 \%$ were living in urban areas. Among the mothers living in urban areas, the likelihood of formula-feeding was significantly associated with maternal educational status and attitude towards formula-feeding. On the other hand, being attended by relatives/friends and the traditional birth attendant was significantly associated with the formula-feeding practice among mothers who live in rural areas.
\end{abstract}

Conclusion: Nearly half of the mothers in the study area practice formula-feeding for their infant. Therefore, sustained community based nutritional health education is recommended for pregnant and lactating mothers to reduce the practice of formula-feeding for infants.

Keywords: Formula-feeding practice, Predictors of formula feeding, Jimma, Ethiopia

\footnotetext{
* Correspondence: ghailay2015@gmail.com

${ }^{2}$ Department of Public Health, College of Health Sciences, Aksum University,

P.O. Box 298, Aksum, Ethiopia

Full list of author information is available at the end of the article
}

(c) The Author(s). 2019 Open Access This article is distributed under the terms of the Creative Commons Attribution 4.0 International License (http://creativecommons.org/licenses/by/4.0/), which permits unrestricted use, distribution, and reproduction in any medium, provided you give appropriate credit to the original author(s) and the source, provide a link to the Creative Commons license, and indicate if changes were made. The Creative Commons Public Domain Dedication waiver (http://creativecommons.org/publicdomain/zero/1.0/) applies to the data made available in this article, unless otherwise stated. 


\section{Background}

The neonatal period represents one of the most critical and vulnerable periods in human life, particularly with respect to nutrition [1]. The newborns are in a state of rapid development and maturation, because the growth rate is most rapid during the first four to 6 months of life. Demands the availability of essential nutrients [2, 3].On the other hand, an infant's tolerance for deviations in food intake is limited because most of the organs that play an essential role in metabolism and its regulation are immature. Other organs such as the central nervous system are also in a process of intensive development and maturation [4-6].

Nutritional inadequacy during the infant period causes prolonged and sometimes irreversible effects on the growth and development and adult physiological function [7]. Another factor which gives rise to specific nutritional problems during this period is that the tendency of children to be monotonous; lacking which results nutritional insufficiency if [8,9]. However, several studies in developing countries indicated that the prevalence and duration of breastfeeding are declining and are being replaced by formula-feeding including plain water, butter, fruits juice and other local foods, while colostrum is discarded as unclean $[10,11]$. These are the families who cannot afford the high cost of formula feeding [11]. A study conducted in Nigeria among children aged below 6 months showed that the proportion of infants who were given formula feeding was $83.6 \%$, [12]. Other similar studies conducted in India, Nepal, and Bangladesh revealed that more than half of the mothers with a child aged below 1 year were formula -feeding their babies [13-15]. Also, in 11 rural villages in Northern India formula -feeding was found to be associated with higher morbidity and mortality compared to children who were breastfed by their mother [13].

Formula-feeding results in many health problems, as it has often led to an increased incidence of childhood conditions. Diarrhea, malnutrition, acute respiratory infection, protein-energy malnutrition, iron deficiency (which leads to mental retardation and keratomalacia) are the main hazards of infants prematurely deprived of their mother's milk and fed on inadequate substitutes in unhygienic conditions [16-18]. In Ethiopia, the proportion of mothers who still breastfeed their infants are considerably low [19]. A study conducted in Southwest Ethiopia showed that the proportion of exclusive breastfeeding was $37.9 \%$ at the end of the first month which dropped to $9.9 \%$ at the age of 6 months [20]. These mothers started using commercially processed, packed infant formula milk and natural cow's milk as a substitution for breast milk. Another study conducted in similar parts of Ethiopia showed that mothers introduced supplementary foods (cow's milk and formula milk) at an average of 2 months [21]. The tendency to use the formula-feeding increased in relation to child or infant increasing age. About $17 \%$ of the infants under the age of 3 months were offered formula and it increased to $69 \%$ in infants from 4 to 6 months [11].

According to the 2011 Ethiopian Demographic Health Survey (EDHS, 2011), 48\% of mothers formula feed their children during the first 6 months after birth. Formulafeeding was $30 \%$ among the age of $0-1$ month, it was $45 \%$ between 2 and 3 months and it increased to $68 \%$ in the infants from 4 to 5 months [19]. Even though early and timely breastfeeding is one of the key components of primary health care in Ethiopia, a wide range of traditional and cultural beliefs related to infant formula-feeding practices are documented even after implementations of the national infant and young child feeding recommendations [19]. However, there are no studies which documented formula-feeding practice and factors associated with formula-feeding practices in the study area particularly in a comparative way. Moreover, the magnitude of formulafeeding is not well studied in relation to the urban and rural basis. Thus, this study assessed the magnitude of formula-feeding practice and associated factors among urban and rural mothers in the Jimma Zone, specifically between the urban and rural part.

\section{Methods}

\section{Study setting and sampling}

A cross-sectional community-based comparative study was carried out in the Jimma zone Oromia region in South West Ethiopia, $327 \mathrm{~km}$ removed from Addis Ababa, based on the figure published by the Central Statistical Agency (CSA) in 2007. The Jimma zone has an estimated total population of 2,800,000 people [22]. A total of 714 mothers having children aged 0 to 6 months were interviewed from November 2015 to January 2016.

The sample size was obtained using a sample size calculation for a comparative cross-sectional study. Residence (being urban or rural) was considered as the main factor for practicing formula-feeding and was used for sample size determination. The sample size was calculated based on the following assumptions: A prevalence of mothers who practiced formula-feeding to their children in the rural area to be $50 \%$ (no previous study in the study setting); a prevalence of mothers who practiced formula-feeding to their children in the urban area to be $35 \%$ (from the previous similar study (21)); a power of $80 \%(0.841)$, a $5 \%$ type I error, a $5 \%$ non response rate and a design effect of 2 for the multistage nature of the sampling technique. Therefore, the final sample size was 714 with one to one ratio (357 mothers from each urban and rural area).

A multistage cluster sampling technique was used to select the respondents from 20 districts of the Jimma 
zone. Since the study units came from the Jimma zone to specific sub-districts, the first group was formed using district as a cluster (both from urban and rural), then based on the WHO recommendation, which is $30 \%$ of the districts (both from urban and rural) were selected through lottery method. In the second stage again 30\% of sub-districts (both from urban and rural) was selected from each district. Sample size for each group was allocated according to the proportion to the number of mothers in the specific sub-districts. Finally, a simple random sampling technique was used in the respective sub-districts to select the study unit. After a list of mothers having children 0-6 months was identified, age identification numbers were taken from the registration book of health extension works in each sub-district. The data collection was continuous until the predetermined sample size obtained (Fig. 1).

This study included mothers who were a permanent resident of the selected sub-districts and had infants aged from 0 to 6 months; however, self-reporting mothers with any medical condition incompatible with breastfeeding including HIV positive were not included.

\section{Measurements}

Data were collected using structured questionnaires which comprised of information on socio-demographic characteristics, knowledge, attitude, and practice regarding infant formula feeding (Additional file 1). The questionnaire was prepared in English after reviewing relevant literatures [20, 21]; translated to Afan Oromo and finally retranslated back to English by a person who can speak both languages. The questionnaire was pre-tested prior to the actual data collection. All necessary modifications were made to the questionnaire including terminologies and formatting based on the pretest findings. The supervisors checked each completed questionnaire and principal investigators monitored the overall quality of the data. In this study, formula- feeding practice was defined as the feeding of an infant less than 6 months old using a formula with a rubber nipple, cup and spoon and other materials on the end as a substitute for or supplement to breastfeeding and it was measured by a "Yes" (1) and "No" (2) question. The mothers who answered "Yes" to the question were considered a mother who feeds their child by formula-feeding.

Environmental or enabling factors are groups of a variable that affect the practice of formula-feeding by mothers. In this study, those variables were measured by availability and affordability of the formula milk. The variable was measured by "Yes" (1) and "No" (2).

Individual factors are those factors that include knowledge and perception towards formula feeding, maternity experience and attitude towards formula-feeding. In this study, knowledge and previous experience were measured using a "Yes" (1) and "No" (2), questioner and the attitude towards formula- feeding was measured by a Likert scale with three labels. The options were "agree" (3), "neutral" (2), and "disagree" (1). All attitude questions were summed up and treated as a continuous variable and those participants with the highest score were considered as having a favorable attitude towards formula-feeding questions.

\section{Data analysis}

Data were entered to the Epi-info Version 3.5.3 and analyzed using SPSS (SPSS Inc. version 21.0, Chicago, Illinois). The socio-demographic and other information was stratified in to rural and urban categories and were descriptively presented by tables. Continuous variable such as age were expressed using mean \pm SD and the categorical forms are presented in the tables. Bi-variate analysis was used to select the best predictor variables and those variables which showed a significant association at a $p$-value of $<0.25$ were entered to the multiple logistic regression models and a $p$-value of $<0.05$ was used to measure the significance in the final predictors

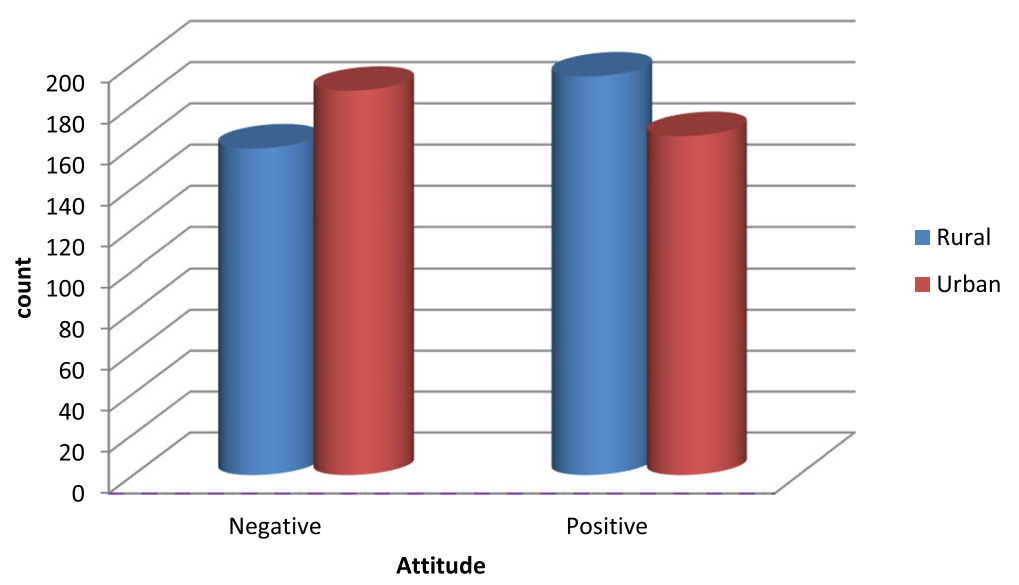

Fig. 1 Sampling technique and procedure for formula-feeding practice in the Jimma zone, Oromia, January 2016 
of formula feeding. Strength and direction of the association were also presented using adjusted odds ratios (AOR) relative to the reference category and using 95\% confidence levels.

\section{Results}

Socio-demographic characteristics of participants

From the overall sample size, 705 mothers (98.7\%) responded to the questionnaire completely. Based on their living arrangements, 352 mothers (49.9\%) were living in urban areas and 353 mothers $(50.1 \%)$ were living in rural areas. The mean age of the respondents was 27.4 years $(\mathrm{SD} \pm 4.7)$, with a minimum age of 16 years and a maximum age of 41 years. The mean age of the children was 3.5 months with a minimum of 1 month and a maximum of 6 months. Regarding the religion of the respondents, 597 mothers (84.7\%) identified as Islam. Regarding educational status, 85 mothers (24.1\%) living in the urban areas and 298 mothers (84.4\%) living in rural areas were illiterate [Table 1].

\section{Maternity experience}

On average, each mother gave birth to 3 children. A total of 309 mothers (87.5\%) in the rural and 296 mothers $(84.1 \%)$ in the urban area attended ANC. About 138 mothers $(46.6 \%)$ in the urban area had four times ANC visit during their last pregnancy (Table 2).

\section{Awareness of mother/care taker on formula-feeding}

The majority of the mothers both in the rural and urban areas heard about the effect of formula-feeding on the health of their child. Diarrhea was mentioned by the majority $(231,53.6 \%)$ of the mothers as a health problem caused by formula feeding, followed by an intestinal parasite $(107,24.8 \%)$ and tonsil $(93,21.6 \%)$. About 85 mothers (24.1\%) in the urban area and 91 mothers (25.8\%) in the rural area have received health education about formula-feeding during their last pregnancy.

\section{Attitude towards formula feeding}

About 178 mothers (50.4\%) in the rural areas and 176 mothers $(50 \%)$ in the urban areas disagreed with the idea that formula-feeding ensures optimal health for the baby. In general, 159 mothers (45\%) in the rural area and 187 mothers (53.2\%) in the urban areas had a negative attitude towards formula-feeding (Table 3), see also Fig. 2.

\section{Social pressure}

The pressure of religious leaders, mothers-in-law, grandmothers/elderly and husbands' relatives was significantly associated with the decision of the mother to formulafeed her children. Social pressure scores were analyzed as a continuous variable with possible values ranging from 3 to 20 for both living arrangements. The mean
Table 1 Frequency distribution of mothers by sociodemographic characteristics, Jimma zone, Oromia January 2016

\begin{tabular}{|c|c|c|c|}
\hline \multirow[t]{3}{*}{ Variables } & \multicolumn{2}{|c|}{ Living arrangements } & \multirow[t]{3}{*}{ Total } \\
\hline & Rural $(N=353)$ & Urban $(N=352)$ & \\
\hline & $N[\%]$ & $N[\%]$ & \\
\hline \multicolumn{4}{|l|}{ Mother /Care taker age } \\
\hline $15-24$ & 59 [16.7] & $108[30.7]$ & 167 \\
\hline $25-34$ & $243[68.8]$ & $222[63]$ & 465 \\
\hline $35-45$ & $51[14.5]$ & 22 [6.25] & 73 \\
\hline \multicolumn{4}{|l|}{ Mother educational status } \\
\hline Illiterate & $298[84.4]$ & $85[24.1]$ & 319 \\
\hline \multirow[t]{5}{*}{ Read and write } & 55 [15.6] & 59 [16.8] & 80 \\
\hline & & $51[14.5]$ & 97 \\
\hline & & 56 [15.9] & 96 \\
\hline & & 61 [17.3] & 73 \\
\hline & & $40[11.4]$ & 40 \\
\hline \multicolumn{4}{|l|}{ Mother marital status } \\
\hline Married & $348[98.6]$ & $333(94.6)$ & 681 \\
\hline Widowed & 0 & $13[3.7]$ & 13 \\
\hline Divorced & $5[1.4]$ & $6[1.7]$ & 11 \\
\hline \multicolumn{4}{|l|}{ Religion } \\
\hline Islam & $320[90.7]$ & $277[78.7]$ & 597 \\
\hline Orthodox & $16[4.5]$ & $59[16.8]$ & 75 \\
\hline Protestant & $17[4.8]$ & $16[4.5]$ & 33 \\
\hline \multicolumn{4}{|l|}{ Ethnicity } \\
\hline Oromo & $321[90.9]$ & $304[86.4]$ & 625 \\
\hline Amhara & 8 [2.3] & $24[6.8]$ & 52 \\
\hline Other ${ }^{a}$ & $24[6.8]$ & $24[6.8]$ & 48 \\
\hline \multicolumn{4}{|l|}{ Mother/care taker occupation } \\
\hline Farmer & $164[6.4]$ & $30[8.5]$ & 194 \\
\hline Governmental employee & $2[0.6]$ & $40[11.4$ & 42 \\
\hline House wife & $178[50.4]$ & $227[64.5]$ & 405 \\
\hline Merchant & $7[2]$ & 48 [11.6] & 55 \\
\hline Other ${ }^{\mathrm{b}}$ & $2[0.6]$ & 7 [2] & 9 \\
\hline
\end{tabular}

${ }^{\mathrm{a} k a f f a}$, Gurage, Yem, Tigirian, Wolayita and dawuro; ${ }^{\mathrm{b}}$ Daily laborers and housekeeper

score of social pressure for mothers living in the urban area was $12.4( \pm 4.6)$ and the mean score for mothers living in the rural areas was $12.3( \pm 4.3)$.

\section{Practice on formula-feeding}

Majority, 218 mothers (61.9\%) in the urban area were practicing formula-feeding for their child. On the other hand, only 115 mothers $(32.6 \%)$ in the rural areas practiced formula-feeding for their child. Among the rural dwellers who practiced formula-feeding (115), the frequency of formula-feeding was one to four times a day in 85 mothers (73.9\%) (Table 4). 
Table 2 Maternity experiences of mothers in Jimma zone, Oromia January 2016

\begin{tabular}{|c|c|c|c|}
\hline \multirow[t]{3}{*}{ Variables } & \multicolumn{2}{|c|}{ Living arrangements } & \multirow[t]{3}{*}{ Total } \\
\hline & Rural $(N=353)$ & Urban $(N=352)$ & \\
\hline & $N[\%]$ & $\mathrm{N}[\%]$ & \\
\hline \multicolumn{4}{|l|}{ ANC Visit } \\
\hline Yes & $309[87.5]$ & $296[84.1]$ & 605 \\
\hline No & $44[12.5]$ & 56 [15.9] & 100 \\
\hline \multicolumn{4}{|l|}{ Number of ANC visit } \\
\hline 1 & $4[1.3]$ & $5[1.7]$ & 9 \\
\hline 2 & $50[16.2]$ & $53[18]$ & 103 \\
\hline 3 & $136[44]$ & 97 [32.7] & 233 \\
\hline 4 & $113[36.6]$ & $138[46.6]$ & 251 \\
\hline I do not know & $6[1.9]$ & $3[1]$ & 9 \\
\hline \multicolumn{4}{|l|}{ PNC follow up } \\
\hline Yes & $248[70.3]$ & $270(76.7)$ & 518 \\
\hline No & 105 [29.7] & 82 [23.3] & 187 \\
\hline \multicolumn{4}{|l|}{ Place of delivery } \\
\hline Home & $166[47]$ & $53[15]$ & 219 \\
\hline Governmental health facility & $177[50.1]$ & $286[81.2]$ & 463 \\
\hline NGOs health facility & $9[2.6]$ & $11[3.2]$ & 20 \\
\hline On the way to health & $1[0.3]$ & $2[0.6]$ & 3 \\
\hline \multicolumn{4}{|l|}{ Facility } \\
\hline \multicolumn{4}{|l|}{ Birth attendants } \\
\hline Health professionals & $183[51.8]$ & $300[85.2]$ & 483 \\
\hline Relatives/friends/neighbors & 138 [39.1] & $39[11.1]$ & 177 \\
\hline TBA/ТTBA & $32[9.1]$ & $13[3.7]$ & 45 \\
\hline
\end{tabular}

ANC Antenatal care, NGOs None Governmental Organizations, PNC Postnatal care, TBA Traditional Birth Attendants, TTBA Trained Traditional Birth Attendants

Bivariate logistic regression analysis of formulafeeding practice among mothers living in the urban and rural areas

The bivariate analysis showed that women in the rural areas were 3.36 times more likely to formula-feed their child than women living in the urban areas. The observed difference was statistically significant [COR = 3.36, (95\%CI2.41-4.58], $P=0.00$ ] (Table 5).

\section{Predictors of formula-feeding practice among mothers living in the rural areas}

In order to determine the influence of each predictor on the formula-feeding practice, all variables that become significant at the bivariate analysis were included in multivariate logistic regression for further analysis. Mothers who heard about the health effect of formula-feeding were $41 \%$ less likely to formula-feed their child. Being attended by traditional birth attendants and relative or friends increases the likelihood of formula-feeding by 48 and $97 \%$ respectively $[\mathrm{AOR}=6.892,95 \% \mathrm{CI}=1.103-43.061, \mathrm{AOR}=$ 8.702, 95\% CI = 1.437-52.709].

For social pressure among mothers living in the rural areas, per a unit increase in a total score of social pressure, the odds of formula-feeding reduces by 0.83 and the observed difference was statistically significant [AOR, 95\%CI .83(.78-.89)] (Table 6).

\section{Predictors of formula-feeding practice among mothers living in the urban areas}

In the bivariate analysis, educational status of the mother, place of delivery, awareness about the health effect of formula feeding, attitude towards formula-feeding and social pressure were significantly associated with formulafeeding practice at $P$ value $<0.05$. By the final model, the educational status of the mother was significantly associated with formula-feeding practice. The likelihood of formula-feeding increases by $39 \%$ among illiterate mothers [AOR $=3.39,95 \% \mathrm{CI} 1.41-8.17]$. Awareness about the health effect of formula-feeding reduces the likelihood of formula-feeding by 0.29 among mothers living in the urban areas $[$ AOR $=.294,95 \%$ CI .167-.517].

Regarding the attitude towards formula-feeding, having negative attitude increases the probability of not formula-feeding by $74 \%[\mathrm{AOR}=2.749$, 95\%CI $1.626-$

Table 3 Attitude towards formula-feeding among mothers in Jimma Zone, Oromia January, 2016

\begin{tabular}{|c|c|c|c|c|c|c|c|}
\hline \multirow[t]{4}{*}{ Item } & \multicolumn{6}{|l|}{ Responses } & \multirow[t]{4}{*}{ Total } \\
\hline & \multicolumn{3}{|c|}{ Rural $(N=353)$} & \multicolumn{3}{|c|}{ Urban $(N=352)$} & \\
\hline & Disagree & Neutral & Agree & Disagree & Neutral & Agree & \\
\hline & $\mathrm{N}[\%]$ & $N[\%]$ & $\mathrm{N}[\%]$ & $\mathrm{N}[\%]$ & $\mathrm{N}[\%]$ & $\mathrm{N}[\%]$ & \\
\hline Formula-feeding ensures optimal health for the baby. & $178[50.4]$ & $58[16.4]$ & $117[33.2]$ & $176[50]$ & $57[16.2]$ & 119 [33.8] & 705 \\
\hline Formula-feeding can causes excessive weight gain in baby. & $176[49.9]$ & $76[21.5]$ & $101[28.6]$ & $194[55.1]$ & $55[15.6]$ & $103[29.3]$ & 705 \\
\hline Formula-feeding is more convenient than breastfeeding. & $191[54.1]$ & $76[21.5]$ & $86[24.4]$ & $245[69.6]$ & $44[12.5]$ & 63 [17.9] & 705 \\
\hline Formula-feeding ensures optimal health for the mother. & $168[47.6]$ & $40[11.3]$ & $145[41.1]$ & $150[42.6]$ & $57[16.2]$ & $145[41.2]$ & 705 \\
\hline Formula-feeding babies tend to be fed less frequently. & $195[55.2]$ & 40 [11.3] & $118[33.5]$ & $173[49.2]$ & $79[22.4]$ & $100[28.4]$ & 705 \\
\hline $\begin{array}{l}\text { The nutritional benefit of breast milk lasts only until the baby } \\
\text { is weaned from breast milk. }\end{array}$ & $222[62.9]$ & $38[10.8]$ & $93[26.3]$ & $180[51.1]$ & $47[13.4]$ & $125[35.5]$ & 705 \\
\hline
\end{tabular}




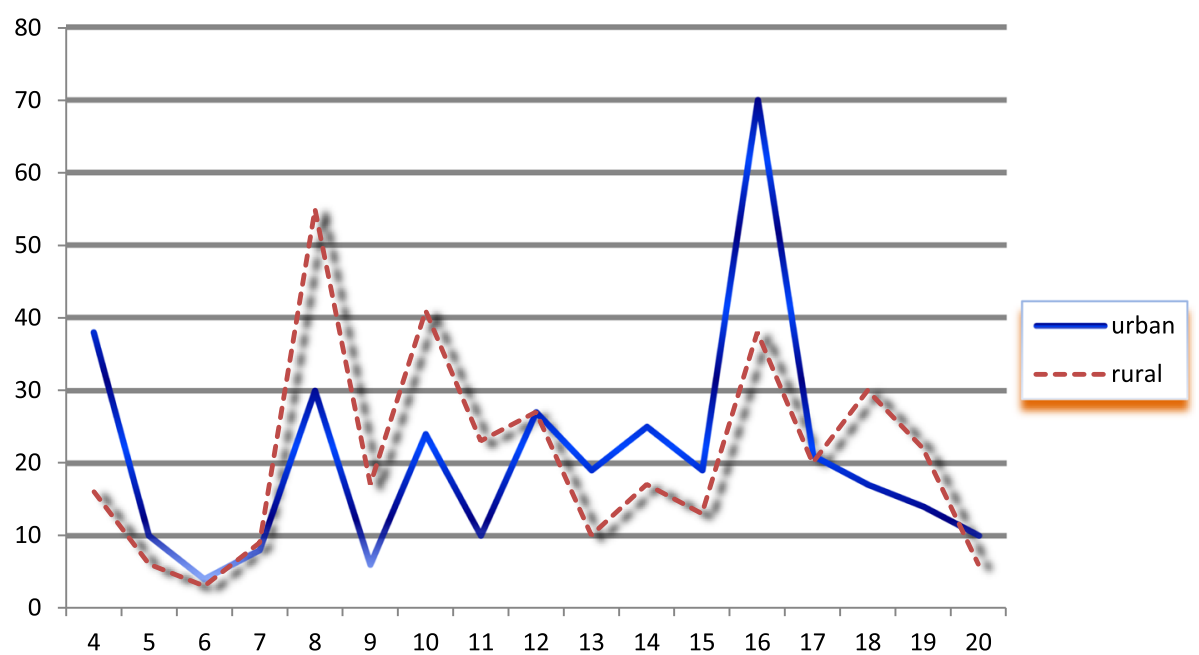

Fig. 2 Mothers' attitude towards formula-feeding in the Jimma zone, Oromia, January 2016

4.648]. A unit decline in social pressure reduces the risk of formula-feeding by $0.925[\mathrm{AOR}=.925,95 \% \mathrm{CI}$, .875-.977] (Table 7).

\section{Discussion}

Formula-feeding is becoming a common practice in various parts of Ethiopia both in urban and rural areas due to various socio-cultural reasons. In this study almost half of the mothers (47.2\%) practiced formula-feeding

Table 4 Formula-feeding practice of mothers in the Jimma zone, Oromia, January 2016

\begin{tabular}{|c|c|c|c|}
\hline \multirow[t]{3}{*}{ Variables } & \multicolumn{2}{|c|}{ Living arrangements } & \multirow[t]{3}{*}{ Total } \\
\hline & Rural $N=353$ & Urban $N=352$ & \\
\hline & $N[\%]$ & $N[\%]$ & \\
\hline \multicolumn{4}{|l|}{ Formula feed } \\
\hline Yes & 115 [32.6] & 218 [61.9] & 333 \\
\hline No & $238[67.4]$ & $134[38.1]$ & 372 \\
\hline \multicolumn{4}{|c|}{ Frequency of formula feeding } \\
\hline Unknown & $7[6.1]$ & $44[20.2]$ & 51 \\
\hline 1 to 4 times & 85 [73.9] & $109[50]$ & 194 \\
\hline 5 and above & $23[20]$ & $65[29.8]$ & 88 \\
\hline \multicolumn{4}{|l|}{ Food introduced first } \\
\hline Cow milk & $83[72.2]$ & $64[29.4]$ & 147 \\
\hline Infant formula & $8[6.9]$ & $98[45]$ & 106 \\
\hline Fruits juice & $8[6.9]$ & $45[20.6]$ & 53 \\
\hline Tea & $16[14]$ & $2[0.9]$ & 18 \\
\hline Other $^{a}$ & 0 & $9[4.1]$ & 9 \\
\hline \multicolumn{4}{|c|}{ Age at first baby start formula feeding } \\
\hline $1-6$ months & 33 [28.7] & $113[51.8]$ & 146 \\
\hline 7 and above months & 82 [71.3] & 105 [48.2] & 187 \\
\hline
\end{tabular}

${ }^{\mathrm{a}}$ Flax seed, fenugreek, and oats juice for their babies, of whom 65.5 and $34.5 \%$ of them were mothers living in the rural and urban areas respectively.

Even though formula-feeding practice was not specifically assessed and it is difficult to make comparisons, non-human milk feeding was 35\% (lower than the current finding) in the general population as to the study conducted in Uganda [23]; non-exclusive breastfeeding was also found to be $57 \%$ in Malawi [24], 49.4\% in Sorro district, southern Ethiopia [25], 28\% in Offa district, southern Ethiopia [26] and 30.1\% in Hawassa town, Southern Ethiopia [27].

Being aware of the health effect of formula-feeding and social pressures was significantly associated with the formula-feeding practice among mothers in both rural and urban settings. This indicates that anyone respected by mothers such as religious leaders, mothers-in-law or grandmothers, husbands and other close relatives have a significant impact on the decision of mothers to formula-feed their child or not.

In addition, mothers who have less awareness about the health effect of formula-feeding on their children

Table 5 Comparison of formula-feeding practice among mothers living in the rural and urban areas in the Jimma zone, January, 2016

\begin{tabular}{|c|c|c|c|}
\hline \multirow[t]{3}{*}{ Variable } & \multicolumn{2}{|c|}{ Formula-feeding practice } & \multirow{3}{*}{$\begin{array}{l}\text { Crude OR } \\
{[95 \% \mathrm{Cl}]}\end{array}$} \\
\hline & Yes & No & \\
\hline & N [\%] & N [\%] & \\
\hline \multicolumn{4}{|c|}{ Living arrangements } \\
\hline Rural & $115[34.5]$ & $238[64]$ & $3.36[2.41-4.58]^{*}$ \\
\hline Urban & $218[65.5]$ & $134[36]$ & 1.00 \\
\hline Total & 333 [100] & $372[100]$ & \\
\hline
\end{tabular}

CI Confidence interval, COR Crude odds ratio; 1: referent; *statisticaly significant at $P<0.05$

All variables with statistical significance have been made in bold face 
Table 6 Bivariate and multivariate analysis of formula-feeding practice among mothers living in the rural areas, Jimma zone, January, 2016

\begin{tabular}{|c|c|c|c|c|}
\hline \multirow[t]{3}{*}{ Variables } & \multicolumn{2}{|c|}{ Formula-feeding practice } & \multirow[t]{3}{*}{ COR(95\% Cl) } & \multirow[t]{3}{*}{$\mathrm{AOR}(95 \% \mathrm{Cl})$} \\
\hline & No $(N=238)$ & Yes $(N=115)$ & & \\
\hline & $\mathrm{N}$ [\%] & $\mathrm{N}$ [\%] & & \\
\hline \multicolumn{5}{|l|}{$\begin{array}{l}\text { Mother /Care } \\
\text { taker age }\end{array}$} \\
\hline $15-24$ & 45 [76.3] & 14 [23.7] & $1.216[.515-2.875]$ & \\
\hline $25-34$ & $156[64.2]$ & $87[3.8]$ & $.678[.348-1.32]$ & \\
\hline $35-45$ & 37 [72.5] & $14[27.5]$ & 1.00 & \\
\hline \multicolumn{5}{|l|}{ Sex of the infant } \\
\hline Male & $121[68]$ & $57[32]$ & $1.05[.67-1.64]$ & \\
\hline Female & 117 [66.9] & $58[33.1]$ & 1.00 & \\
\hline \multicolumn{5}{|l|}{$\begin{array}{l}\text { Educational status } \\
\text { of Mother }\end{array}$} \\
\hline Illiterate & 109 [36.6] & 189 [63.4] & $.212[.088-.512]$ & $.186[.072-.481]$ \\
\hline Read and write & $6[10.9]$ & $49[89.1]$ & 1 & \\
\hline \multicolumn{5}{|l|}{ Ethnicity } \\
\hline Oromo & $216[67.3]$ & 105 [32.7] & 1.00 & \\
\hline Amhara & $4[50]$ & $4[50]$ & $.486[.119-1.82]$ & \\
\hline Others & 18 [75] & $6[25]$ & $1.45[.562-3.78]$ & \\
\hline \multicolumn{5}{|l|}{ Mother occupation } \\
\hline Farmer & 124 [75.6] & $40[24.4]$ & 1.00 & 1.00 \\
\hline House wife & $105[59]$ & $73[41]$ & $.464[.29-.739]^{*}$ & $0.405[.243-.675]$ \\
\hline Governmental & $9[81.8]$ & $2[18.2]$ & $1.452[.30-6.99]$ & $0.583[.108-3.159]$ \\
\hline \multicolumn{5}{|l|}{ Employee } \\
\hline \multicolumn{5}{|l|}{ ANC visit } \\
\hline Yes & $210[68]$ & $99[86.1]$ & 1.00 & \\
\hline No & $28[11.8]$ & 16 [13.9] & $.825[0.427-1.595]$ & \\
\hline \multicolumn{5}{|l|}{ PNC visit } \\
\hline Yes & $171[71.8]$ & $73[63.5]$ & 1.00 & \\
\hline No & 67 [28.2] & $42[36.5]$ & $.681[.424-1.093]$ & \\
\hline \multicolumn{5}{|l|}{ Place of delivery } \\
\hline Home & $131[55.3]$ & $35[30.4]$ & $2.825[1.761-4.531]^{*}$ & $399[.069-2.326]$ \\
\hline Health facility & $106[44.7]$ & $80[69.6]$ & 1.00 & \\
\hline \multicolumn{5}{|l|}{ Birth attendants } \\
\hline Health worker & $131[55.3]$ & $80[69.5]$ & 1.00 & 1.00 \\
\hline ТТВA/TBA & $21[8.8]$ & $8[7]$ & 2.039 [.858-4.893] & $6.892[1.103-43.061]^{*}$ \\
\hline Relative/Friends. & 114 [39.9] & $27[23.5]$ & $3.279[1.967-5.468]^{*}$ & $8.702[1.437-52.709]^{*}$ \\
\hline \multicolumn{5}{|l|}{$\begin{array}{l}\text { Awareness about } \\
\text { formula feeding }\end{array}$} \\
\hline Yes & $172[72.3]$ & $50[43.5]$ & 1.00 & \\
\hline No & $66[27.7]$ & $65[56.5]$ & $3.38[2.127-5.395]^{*}$ & $.401[.237-.677]^{*}$ \\
\hline \multicolumn{5}{|l|}{$\begin{array}{l}\text { Attitude towards } \\
\text { formula feeding }\end{array}$} \\
\hline Positive & $125[53.4]$ & $67[58.3]$ & 1.00 & \\
\hline Negative & $111[46.6]$ & $48[41.7]$ & $1.220[.778-1.913]$ & \\
\hline Social pressure & & & $0.831[.784-.881]^{*}$ & $.837[.780-.898]^{*}$ \\
\hline
\end{tabular}

ANC Antenatal Care, AOR Adjusted odds ratio, CI Confidence interval, COR Crude odds ratio, PNC Postnatal care, TBA Traditional birth attendant, $T$ TBA Trained traditional birth attendant; 1: referent; *significant at $p$ value $<0.05$

All variables with statistical significance have been made in bold face 
Table $7 \mathrm{Bi}$ and multivariate analysis of formula-feeding practice among mothers living in the urban areas, Jimma zone, January, 2016

\begin{tabular}{|c|c|c|c|c|}
\hline \multirow[t]{3}{*}{ Variables } & \multicolumn{2}{|c|}{ Formula-feeding practice } & \multirow[t]{3}{*}{$\operatorname{COR}(95 \% \mathrm{Cl})$} & \multirow[t]{3}{*}{ AOR $(95 \% \mathrm{Cl})$} \\
\hline & No $(N=134)$ & Yes $(N=218)$ & & \\
\hline & N [\%] & N [\%] & & \\
\hline \multicolumn{5}{|c|}{ Mother /Care taker age } \\
\hline $15-24$ & $42[38.9]$ & $66[61.1]$ & $2.164[.742-6.305]$ & \\
\hline $25-34$ & $87[39.2]$ & $135[60.8]$ & $2.191[.78-6.155]$ & \\
\hline $35-45$ & $5[22.7]$ & 17 [77.3] & 1.00 & \\
\hline \multicolumn{5}{|l|}{ Sex of child } \\
\hline Male & $64[37.2]$ & 108 [62.8] & $.931[.602-1.432]$ & \\
\hline Female & 70 [33.9] & 110 [61.1] & 1.00 & \\
\hline \multicolumn{5}{|c|}{ Educational status of the Mother } \\
\hline Illiterate & $44[51.8]$ & $44[48.2]$ & $2.50[1.126-5.567]^{*}$ & $3.39[1.410-8.179]^{*}$ \\
\hline Read and write & $18[30.5]$ & $41[69.5]$ & $1.024[.427-2.456]$ & $1.029[.38-2.77]$ \\
\hline Grade [1-4] & $21[41.2]$ & $30[58.8]$ & $1.633[.680-3.924]$ & $1.705[.662-4.388]$ \\
\hline Grade [5-8] & 16 [28.6] & $40[71.4]$ & $.933[.383-2.275]$ & $.872[.336-2.261]$ \\
\hline Grade [9-12] & $23[37.7]$ & $38[62.3]$ & $1.412[.603-3.310]$ & $1.397[.563-3.466]$ \\
\hline Above 12 & $12[30]$ & $28[70]$ & 1.00 & 1.00 \\
\hline \multicolumn{5}{|l|}{ Religion } \\
\hline Islam & 106 [38.3] & $171[61.7]$ & 1.00 & \\
\hline Orthodox & 19 [32.2] & $40[67.8]$ & $.766[.422-1.393]$ & \\
\hline Protestant & $9[56.2]$ & $7[43.8]$ & 2.074 [.750-5.735] & \\
\hline \multicolumn{5}{|l|}{ Ethnicity } \\
\hline Oromo & 118 [38.8] & 186 [61.2] & 1.00 & \\
\hline Amhara & $6[25]$ & $18[75]$ & $.525[.203-1.362]$ & \\
\hline Other & 18 [75] & $6[25]$ & $1.126[.482-2.618]$ & \\
\hline \multicolumn{5}{|l|}{ Mother occupation } \\
\hline Farmer & $14[46.7]$ & 16 [53.3] & 1.00 & \\
\hline House wife & 80 [35.5] & 147 [64.8] & $.622[.289-1.340]$ & \\
\hline Other & $40[42.1]$ & $55[57.9]$ & $.831[.346-1.896]$ & \\
\hline \multicolumn{5}{|l|}{ ANC visit } \\
\hline Yes & 111 [37.5] & 185 [62.5] & 1.00 & \\
\hline No & $23[41.1]$ & 33 [58.9] & $1.162[.649-2.08]$ & \\
\hline \multicolumn{5}{|l|}{ PNC visit } \\
\hline Yes & 105 [38.9] & 165 [61.1] & 1.00 & \\
\hline No & $29[35.4]$ & $53[64.6]$ & .860 [.514-138] & \\
\hline \multicolumn{5}{|l|}{ Place of delivery } \\
\hline Home & $27[50.9]$ & 26 [49.1] & $1.844[1.02-3.3]^{*}$ & $1.857[.954-3.61]$ \\
\hline Health facility & $107[36]$ & $190[64]$ & 1.00 & \\
\hline \multicolumn{5}{|l|}{ Birth attendants } \\
\hline Health worker & 110 [36.7] & 190 [63.3] & 1.00 & \\
\hline ТTВA/TBA & $7[53.8]$ & $6[46.2]$ & $2.015[.661-6.148]$ & \\
\hline Relative/Friends. & $17[43.6]$ & $22[56.4]$ & $1.335[.680-2.622]$ & \\
\hline \multicolumn{5}{|c|}{ Awareness about formula feeding } \\
\hline Yes & $95[45.5]$ & $114[54.5]$ & 1.00 & 1.00 \\
\hline
\end{tabular}


Table $7 \mathrm{Bi}$ and multivariate analysis of formula-feeding practice among mothers living in the urban areas, Jimma zone, January, 2016 (Continued)

\begin{tabular}{|c|c|c|c|c|}
\hline \multirow[t]{3}{*}{ Variables } & \multicolumn{2}{|c|}{ Formula-feeding practice } & \multirow[t]{3}{*}{ COR $(95 \% \mathrm{Cl})$} & \multirow[t]{3}{*}{ AOR $(95 \% \mathrm{Cl})$} \\
\hline & No $(N=134)$ & Yes $(N=218)$ & & \\
\hline & $\mathrm{N}[\%]$ & $\mathrm{N}[\%]$ & & \\
\hline No & $639[27.3]$ & $104[72.7]$ & $.450[.285-.711]^{*}$ & $.294[.167-.517]^{*}$ \\
\hline \multicolumn{5}{|c|}{ Attitude towards formula feeding } \\
\hline Positive & $44[2.7]$ & 121 [73.3] & 1.00 & 1.00 \\
\hline Negative & $90[48.1]$ & $97[51.9]$ & $2.55[1.629-3.9]^{*}$ & $2.75[1.626-4.6]^{*}$ \\
\hline Social pressure & & & $0.948[.90-.993]^{*}$ & $.925[.875-.977]^{*}$ \\
\hline
\end{tabular}

ANC Antenatal Care, OR Odds ratio, AOR Adjusted odds ratio, CI Confidence interval, COR Crude odds ratio, PNC Postnatal care, TBA Traditional birth attendant, 1 : referent; ${ }^{*}$ significant at $p$ value $<0.05$

All variables with statistical significance have been made in bold face

turned out to have increased formula-feeding practices. Supporting this finding, a study conducted in Eastern Ethiopia found that mothers whose knowledge is low on infant and child feeding practices and those with no access to healthcare facility were more likely to practice non-exclusive breastfeeding, implicating the low awareness on the health effect of formula-feeding [28]. On the other hand, a study conducted in the Offa district, southern Ethiopia supported this finding; those mothers who were able to read and write and those who were aware of exclusive breastfeeding were 1.1 and 6 times more likely to exclusively breastfeed their baby [26] Therefore, the knowledge of the mothers could be a prominent reason of formula-feeding practice during the early infancy; that is why illiterate mothers are 3.39 times more likely to formula-feed their infants. Moreover, their level of knowledge might have affected their attitude towards formula-feeding (AOR: 2.749; 95\% CI: 1.626-4.648).

Regarding the delivery attendant, delivery attended by TBA/relatives/friends/neighbor was an increasing factor for formula-feeding among mothers in the rural areas. This may be due to information given to mothers following delivery about exclusive breastfeeding and the health impact of formula-feeding. In line with this finding, no antenatal care (AOR: 2.6; 95\% CI: 1.64-4.10) during the last pregnancy and no postnatal care (AOR: 1.9; 95\% CI: 1.19-3.04) were significant factors for non-exclusive breastfeeding [25]. According to the study conducted in Hawassa South Ethiopia, mothers who delivered at a health care facility [AOR: 8.8; CI: 5.04-15.4) were more likely to practice exclusive breastfeeding [27]. This means that home delivery could be a major contributor for non-exclusive breastfeeding large fraction of the infants (35.1\%) took liquid forms of food that may define formula-feeding [27].

\section{Conclusion}

Nearly half of the mothers in the study area, majorly mothers living in urban areas, practice formula-feeding for their infant. Being aware about the health effect of breastfeeding and having minimal social pressure decreases the likelihood of formula-feeding practice among mothers in both settings. Illiterate mothers and mothers who had a positive attitude towards formula-feeding were more likely to formula feed their child in the urban areas. A birth attended by relatives/friends/traditional birth attendants' increases the likelihood of formula-feeding among mothers living in the rural area. Therefore, Zonal and district health offices and organizations working on maternal and child health should work to create awareness on the health effect of formula-feeding on infants; design tailored communication to change the attitude of the mothers on formulafeeding and they should work to reduce the influence of social pressure on mothers, by creating awareness among the social cycle could reduce formula-feeding practices in the study area.

\section{Supplementary information}

Supplementary information accompanies this paper at https://doi.org/10. 1186/s12887-019-1789-8.

Additional file 1. Questionnaire: English version

\section{Abbreviations}

ANC: Antenatal Care; DHS: Demographic and Health Survey; FMOH: Federal Ministry of Health; HEW: Health Extension Worker; MCH: Maternal Child Health; NGO: Non-Governmental OrganizationPNCPost-Natal Care;

TBA: Traditional Birth Attendants; TTBA: Trained Traditional Birth Attendants; USA: United State of America; WHO: World Health Organization

\section{Acknowledgements}

We are thankful to Jimma zone for their positive responses to facilitate the study and all the study participants who voluntarily participated in this study.

Authors' contributions

LA, MA, SA, and AM wrote the proposal, participated in data collection, analyzed the data and drafted the paper. LA, MA, SA, AM, MT and HG approved the proposal with great revisions, participated in data analysis and revised subsequent drafts of the paper. All authors read and approved the final manuscript. 


\section{Funding}

This work was funded by Jimma University College of Health Sciences. The funder has financially supported the process of data collection.

\section{Availability of data and materials}

The datasets used and/or analysed during the current study available from the corresponding author on reasonable request.

\section{Ethics approval and consent to participate}

Ethical approval and clearance were obtained from the Jimma University College of Health Science Ethical Clearance Board. A permission letter was also obtained from the Jimma zone Health office and was presented to all participants and stakeholders. Written consent was obtained from all participants. In addition to written consent, verbal consent was also obtained from all uneducated participants. For the study participants under 16 years of age, written assent was obtained from their parents/guardians. Completed consent forms were detached from the questionnaire, a copy being given to the participant, and kept in a locked cabinet on completion of the interview.

\section{Consent for publication}

\section{Not applicable}

\section{Competing interests}

The authors declare that they have no competing interests.

\section{Author details}

'Departments of Health Education and Behavioral Sciences, Jimma University, Jimma, Ethiopia. 'Department of Public Health, College of Health Sciences, Aksum University, P.O. Box 298, Aksum, Ethiopia. ${ }^{3}$ Department of Medical Laboratory Science, College of Health Sciences, Aksum University, Aksum, Ethiopia.

Received: 25 September 2018 Accepted: 16 October 2019 Published online: 04 November 2019

\section{References}

1. Rossman $\mathrm{CL}$, Ayoola AB. Promoting individualized breastfeeding experiences. MCN Am J Matern Child Nurs. 2012;37(3):193-9.

2. Malina RM, Bouchard C, Bar-Or O. Growth, maturation, and physical activity. In: Human kinetics; 2004

3. Huebner G, Boothby N, Aber JL, Darmstadt GL, Diaz A, Masten AS, Yoshikawa H, Redlener I, Emmel A, Pitt M, Arnold L. Beyond survival: the case for investing in young children globally: NAM Perspectives; 2016.

4. WHO: Global Strategy for Infant and Young Child Feeding. In A joint WHO/UNICEF statement. Geneva: WHO; 2003. www.who.int/nutrition/.

5. Mullany LC, Katz J, Li YM, Khatry SK, LeClerq SC, Darmstadt GL, Tielsch JM. Breast-feeding patterns, time to initiation, and mortality risk among newborns in southern Nepal. J Nutr. 2008;138(3):599-603.

6. Lamberti LM, Fischer Walker CL, Noiman A, Victora C, Black RE. Breastfeeding and the risk for diarrhea morbidity and mortality. BMC Public Health. 2011;11(Supplement 3):S15 published 13 April 2011.

7. Rengma MS, Bose K, Mondal N. Socio-economic and demographic correlates of stunting among adolescents of Assam, North-East India. AnthropologicAl Rev. 2016;79(4):409-25.

8. American Academy of Pediatrics Section on Breastfeeding. Breastfeeding and the use of human milk. Pediatrics. 2005;115:496-506

9. World Health Organization. Acceptable medical reasons for use of breastmilk substitutes. Geneva: World Health Organization; 2009.

10. Sinhababu A, Mukhopadhyay DK, Panja TK, Saren AB, Mandal NK, Biswas AB. Infant- and young child-feeding practices in Bankura district, West Bengal, India. J Health Popul Nutr. 2010;28(3):294-9.

11. Shamim S, Jamalvi S, Naz F. Determinants of bottle use amongst economically disadvantaged mothers. J Ayub Med Coll Abbottabad. 2015:18(1):1-4.

12. Kingsley EA, Michael JD, Justice IO, Sunday MO. Determinants of exclusive breastfeeding among aged blow 6 months children in Nigeria. BMC Pregnancy Childbirth. 2011;11(2):1471-2393.

13. Patel A, Badhoniya N, Khadse S, Senarath U, Agho KE, Dibley MJ, The SAIFRN. Infant and young child feeding indicators and determinants of poor feeding practices in India: a review of National Family Health Survey data. Food Nutr Bull. 2010;31(2):314-33.
14. Pandey S, Tiwari K, Senarath U, Agho KE, Dibley MJ, SAIFRN. Determinants of infant and young child feeding practices in Nepal: secondary analysis of demographic and health survey 2006 data. Food Nutr Bull. 2010;31(2):334-51.

15. Mihrshahi S, Kabir I, Roy SK, Agho KE, Senarath U, Dibley MJ, The SAIFRN. Determinants of breastfeeding and infant feeding practices in Bangladesh: secondary analysis of demographic and health survey 2004. Food Nutr Bull. 2010;31(2):334-51.

16. Peters JC, Wyatt HR, Foster GD, Pan Z, Wojtanowski AC, Vander Veur SS, Herring SJ, Brill C, Hill JO. The effects of water and non-nutritive sweetened beverages on weight loss during a 12-week weight loss treatment program. Obesity. 2014;22(6):1415-21.

17. Stuebe A. The risks of not breastfeeding for mother and infants. Rev Obstet Gynecol. 2009;2(4):222-31.

18. Li RW, Magadia J, Fein SB, Grummer-Strawn LM. Risk of bottle-feeding for rapid weight gain during the first year of life. Arch Pediatr Adolesc Med. 2012;166(5):431-6.

19. Central Statistical Agency (CSA) [Ethiopia] and ICF Macro. Ethiopia Demographic and Health Survey 2011. Addis Ababa and Calverton: Central Statistical Agency and ICF Macro; 2012.

20. Dessalegn T, Tefera B, Eskindir L, Shikur M. Sub-optimal breastfeeding of infants and associated factors in Southwest Ethiopia. BMC Public Health. 2012;12(363):1471-2458

21. Andea F, Nida H, Jira C. Infant formula-feeding practice, Agaro Town, Southwest Ethiopia. Ethiopian Journal of Health Sciences. 2003; 13(2).

22. Central Statistical Agency: Summary of statistical report of 2007; population and housing census. In Addis Ababa: CSA; 2008.

23. Fadnes LT, Engebretsen MS, Wamani H, Semiyaga NB, Tylleskär T, Tumwine JK. Infant feeding among HIV-positive mothers and the general population mothers: comparison of two cross-sectional surveys in eastern Uganda. BMC Public Health. 2009:9:124.

24. Kuchenbecker J, Jordan I, Reinbott A, Herrmann J, Jeremias T, Kennedy G, Muehlhoff E, Mtimuni B, Krawinkel MB. Exclusive breastfeeding and its effect on growth of Malawian infants: results from a cross-sectional study. Paediatr Int Child Health. 2015:35(1):14-23.

25. Tadesse T, Mesfin F, Chane T. Prevalence and associated factors of nonexclusive breastfeeding of infants during the first six months in the rura area of Sorro District, Southern Ethiopia: a cross-sectional study. Int Breastfeed J. 2016:11:25

26. Lenja A, Demissie T, Yohannes B, Yohannis M. Determinants of exclusive breastfeeding practice to infants aged less than six months in Offa district, Southern Ethiopia: a cross-sectional study. Int Breastfeed J. 2016;11:32.

27. Adugna B, Tadele H, Reta F, Berhan Y. Determinants of exclusive breastfeeding in infants less than six months of age in Hawassa, an urban setting, Ethiopia. Int Breastfeed J. 2017;12:45

28. Egata G, Berhane $Y$, Worku A. Predictors of non-exclusive breastfeeding at 6 months among rural mothers in East Ethiopia: a community-based analytical cross-sectional study. Int Breastfeed J. 2013:8:8.

\section{Publisher's Note}

Springer Nature remains neutral with regard to jurisdictional claims in published maps and institutional affiliations.

Ready to submit your research? Choose BMC and benefit from:

- fast, convenient online submission

- thorough peer review by experienced researchers in your field

- rapid publication on acceptance

- support for research data, including large and complex data types

- gold Open Access which fosters wider collaboration and increased citations

- maximum visibility for your research: over $100 \mathrm{M}$ website views per year

At $\mathrm{BMC}$, research is always in progress.

Learn more biomedcentral.com/submission 